Tohoku J. exp. Med., 1976, 118, 283-288

\title{
Indication of Mediastinal Lymph Nodes Metastases by Radioaerosol Inhalation Lung Scanning in Pulmonary Neoplasm
}

\author{
Toyoharu Isawa, Koichi OKubo, Takeo Teshima, Tomio \\ Hirano and Kiyoshi Konno \\ Department of Medicine, Divisions of Nuclear Medicine and \\ Pulmonary Physiology, The Research Institute for Tuberculosis, \\ Leprosy and Cancer, Tohoku University, Sendai
}

\begin{abstract}
Isawa, T., Okubo, K., Teshmma, T., Hirano, T. and Konno, K. Indication of Mediastinal Lymph Nodes Metastases by Radioaerosol Inhalation Lung Scanning in Pulmonary Neoplasm. Tohoku J. exp. Med., 1976, 118 (3), 283-288 — Fifty-three patients with pulmonary neoplasm were studied by radioaerosol inhalation and perfusion lung scans, bronchoscopy and spirometry. The probability of lymph node metastases could be estimated by the amount of inhaled aerosol deposited at the carina. On thoracotomy, actual mediastinal lymphadenopathy was minimum, if any, in 4 patients without carinal aerosol deposition. Application of the aerosol inhalation lung scan to pulmonary neoplasm provides useful diagnostic and prognostic information regarding mediastinal lymph nodes metastases. —_ aerosol inhalation lung scan; perfusion; carinal deposition; metastasis
\end{abstract}

Radioaerosol inhalation lung scanning is useful for the diagnosis and evaluation of pulmonary embolism (Isawa et al. 1971b) and obstructive airways disease (Dore et al. 1968; Isawa et al. 1970a). In pulmonary embolism, aerosol is deposited in the non-perfused areas of the lungs indicating the presence of ventilation (Isawa et al. 1971b). In obstructive airways disease, characteristic aerosol deposition patterns are helpful to the classification of chronic obstructive broncho-pulmonary diseases (Isawa et al. 1970a).

Radioaerosol inhalation lung scanning has been applied in patients with pulmonary neoplasm. We have found it a useful non-traumatic way of indicating functional and structural abnormalities of the carina due to lymph node metastases.

\section{Materials and Methods}

Fifty-three patients with pulmonary neoplasm were studied. 45 patients were male and 8 female. Their age ranged from 31 to 81 with an average of 57. Diagnosis was established by sputum cytology, bronchial brushing and/or biopsy specimens from the tumor site or the scalene nodes. There were 50 patients with primary lung tumor; 24 with squamous

Received for publication, October 14, 1975.

Supported by grants ( $\$ 887039$ for $1973, \$ 937031$ for 1974 ) from the Ministry of Education. 
cell carcinoma, 16 adenocarcinoma, 7 small cell carcinoma, 1 large cell carcinoma and 2 bronchial carcinoid and 3 metastatic lung tumor ( 2 adenocarcinoma of the kidney, and 1 medullary carcinoma of the thyroid).

Fiberoptic bronchoscopy was done within 1 or 2 days from the time of inhalation and perfusion lung scanning. Spirometry and inhalation and perfusion lung scans were done either at the same visit or one day apart using ${ }^{8 \theta \mathrm{m}} \mathrm{Tc}$-albumin aerosol for inhalation and ${ }^{131} \mathrm{I}$ - or ${ }^{90 \mathrm{~m}} \mathrm{Tc}-\mathrm{MAA}$ for perfusion. ${ }^{99} \mathrm{~m}$ Tc-MAA was used when perfusion and inhalation scans were done on a different day. Aerosol inhalation and injection of the tracer material for perfusion studies were carried out with the patient in the sitting position. Aerosol for inhalation was generated by an ultrasonic nebulizer* (Isawa et al. 1970a, 1971b). The instrument for lung scanning was either a rectilinear scanner $\dagger$ or a scintillation camera. $\ddagger$

Ten patients with chronic obstructive lung diseases such as pulmonary emphysema, chronic bronchitis and bronchial asthma (Amer. Thorac. Soc. 1962) and 60 patients with miscellaneous lung diseases such as bronchiectasis, sarcoidosis, pneumonia, pneumothorax were studied by spirometry and aerosol inhalation and perfusion lung scanning.

In these patients fiberoptic bronchoscopy was done only when a neoplasm was strongly suspected. Chest radiograms were obtained immediately before or after the scanning procedure.

Operative findings and postoperative courses were compared with findings of the aerosol inhalation lung scan and bronchoscopy in 12 patients.

\section{Results}

Of the 53 patients with pulmonary neoplasm, 25 had normal values of the per cent forced expiratory volume in the first one second $\left(\% \mathrm{FEV}_{\mathbf{1 . 0}}\right)$ greater than or equal to $(\geqq) 70 \%$, and 28 had abnormal values of less than $(<) 70 \%$. There was a good correlation between excessive carinal deposition of inhaled radioactivity and the bronchoscopic observation of a widened carina in pulmonary neoplasm as shown in Table 1. The widened carina was either completely or partially immobile with respiration. When the carina was widened and immobile, there was excessive deposition of radioactivity at the carina (Fig. 1), and a lesser amount when the widened carina was partially mobile. When the carina was normal, there was no detectable radioactive deposition at the carina (Fig. 2).

Twelve of 14 patients with normal values of $\% \mathrm{FEV}_{\mathbf{1 . 0}} \geqq 70 \%$ showed widened carinas bronchoscopically. Also 10 of 11 patients having normal $\% \mathrm{FEV}_{\mathbf{1 . 0}} \geqq 70 \%$

TABLE 1. Comparison of carinal aerosol deposition on aerosol inhalation lung scans and carinal widening by bronchoscopy

\begin{tabular}{|c|c|c|c|c|c|c|}
\hline \multicolumn{3}{|c|}{$\% \mathrm{FEV}_{1.0} \geq 70: 25$ patients } & \multicolumn{4}{|c|}{$\% \mathrm{FEV}_{1.0}<70: 28$ patients } \\
\hline $\begin{array}{l}\text { Carinal deposition } \\
\text { (Scan) }\end{array}$ & \multicolumn{2}{|c|}{$\begin{array}{l}\text { Carinal widening } \\
\text { (Bronchoscopy) }\end{array}$} & \multicolumn{2}{|c|}{$\begin{array}{l}\text { Carinal deposition } \\
\text { (Scan) }\end{array}$} & \multicolumn{2}{|c|}{$\begin{array}{c}\text { Carinal widening } \\
\text { (Bronchoscopy) }\end{array}$} \\
\hline Yes 14 & $\begin{array}{l}\text { Yes } \\
\text { No }\end{array}$ & $\begin{array}{l}12(86 \%) \\
2\end{array}$ & Yes & 24 & $\begin{array}{l}\text { Yes } \\
\text { No }\end{array}$ & $\underset{3}{21}(88 \%)$ \\
\hline No 11 & $\begin{array}{l}\text { Yes } \\
\text { No }\end{array}$ & $\stackrel{1}{10(91 \%)}$ & No & 4 & $\begin{array}{l}\text { Yes } \\
\text { No }\end{array}$ & $\begin{array}{l}1 \\
3(75 \%)\end{array}$ \\
\hline
\end{tabular}

* Mistogen EN142, Mistogen Equipment Company, Oakland, Calif., U.S.A.

$\dagger$ SCC-30, Shimadzu, Kyoto, Japan.

$\ddagger$ RC-1C-1205D-2, Hitachi Medical Corporation, Tokyo, Japan. 

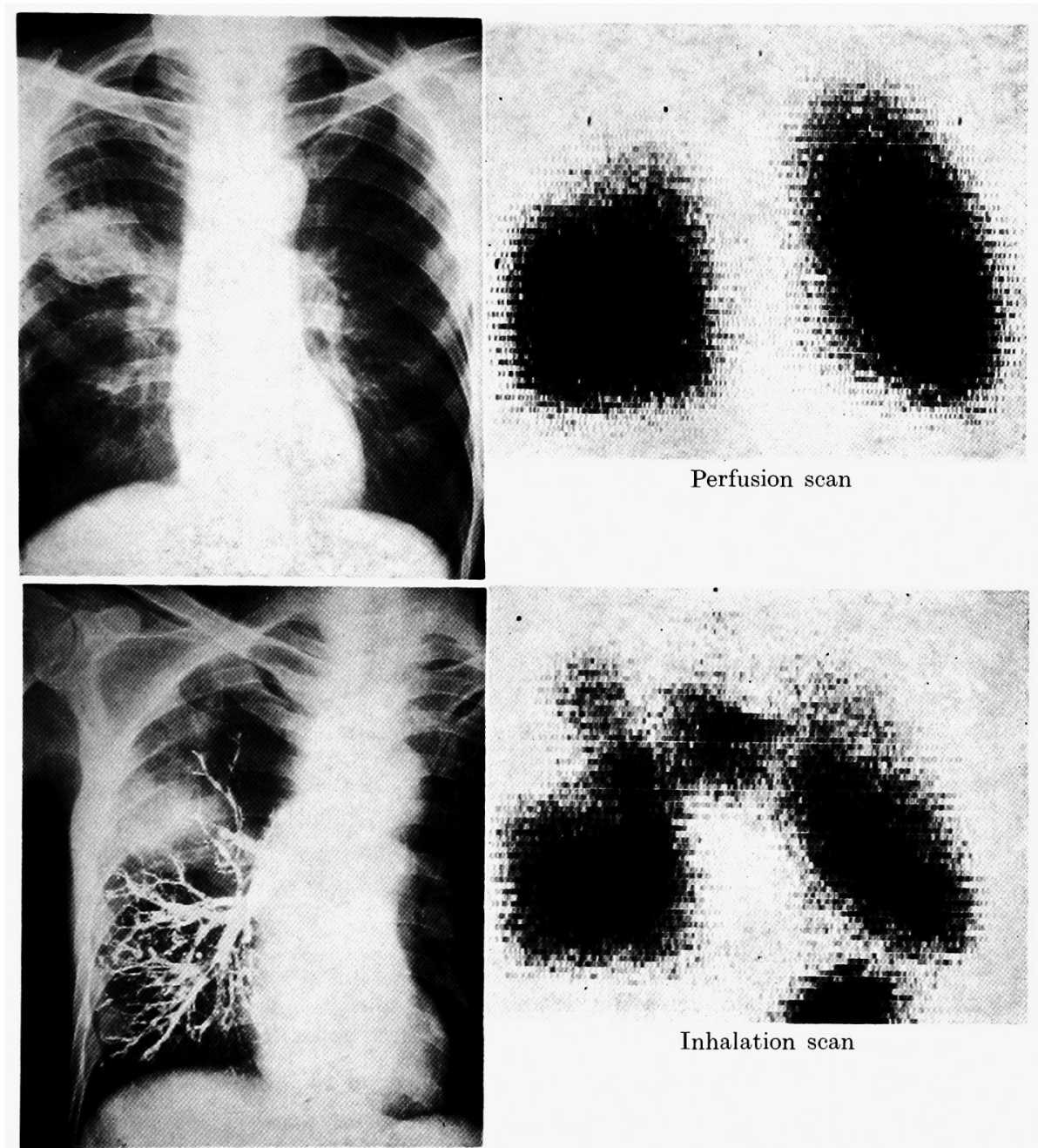

Inhalation scan

Fig. 1. A chest radiogram, a bronchogram and perfusion and aerosol inhalation lung scans of a 64-year-old male with small cell carcinoma of the right upper lobe bronchus. The $\% \mathrm{FEV}_{1.0}$ was $70 \%$.

values and no carinal deposition had normal carinas bronchoscopically. 21 of 24 patients with low \% $\mathrm{FEV}_{1.0}$ and excessive carinal aerosol deposition had widened carinas bronchoscopically. 3 of 4 patients with low $\% \mathrm{FEV}_{\mathbf{1 . 0}}$ values but no carinal aerosol deposition had normal bronchoscopic findings. Thus in 46 of 53 patients with pulmonary neoplasm, an abnormal versus a normal carina could be distinguished by the amount of inhaled aerosol deposited at the carina. In this sense the diagnostically positive rate was $87 \%(46 / 53)$. In the other 7 patients, excessive carinal deposition was found despite bronchoscopically normal finding; i.e., 5 of 53 false positives. In the remaining 2 patients, no carinal deposition was found, although the carina was widened bronchoscopically. These were false negatives 


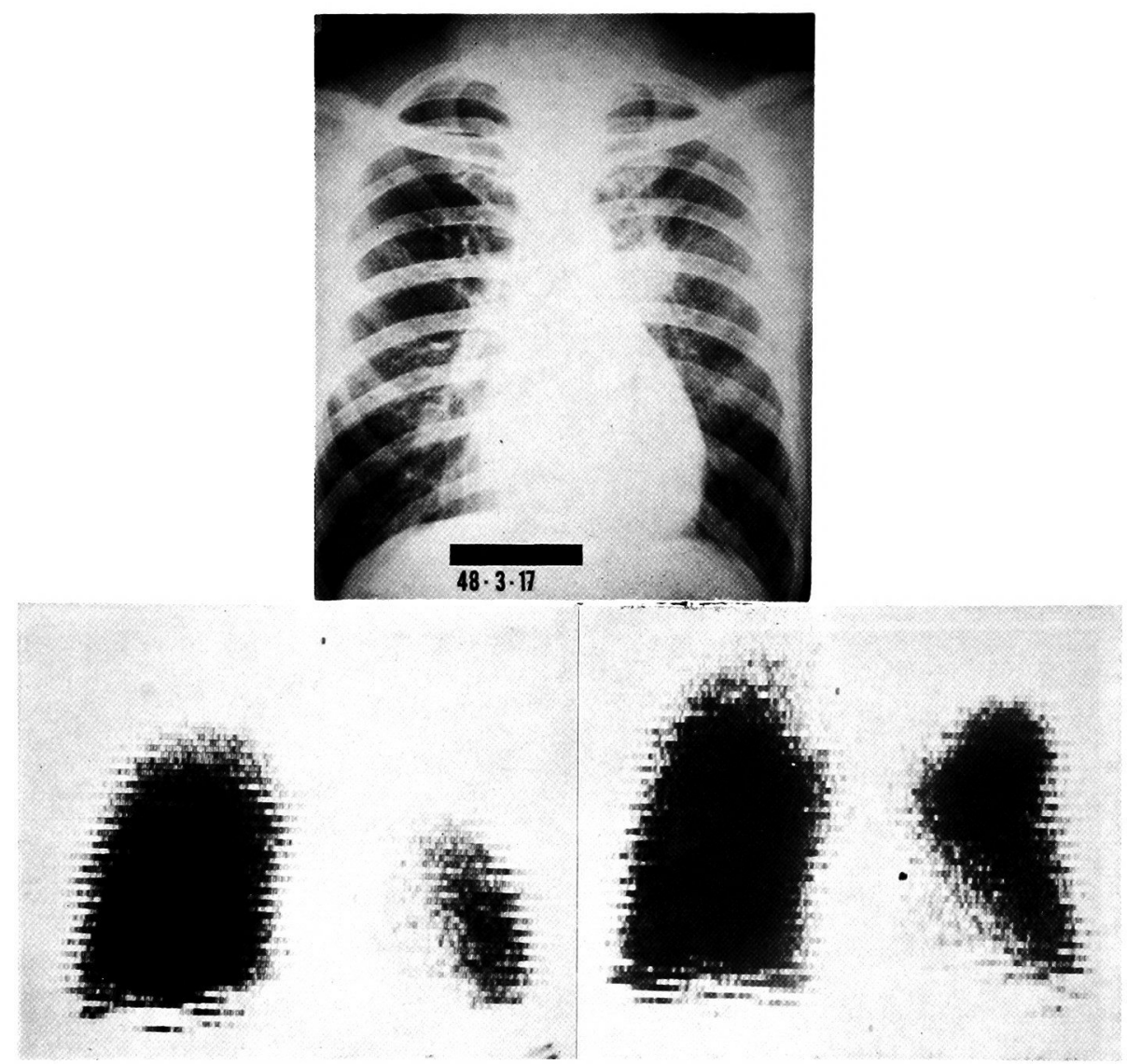

Fig. 2. A chest radiogram and perfusion and aerosol inhalation lung scans of a 45-yearold male with squamous cell carcinoma of the left upper lobe bronchus. The \% $\mathrm{FEV}_{1.0}$ was $65 \%$.

diagnostically.

In the 5 patients with false positive results, 4 were operated upon and 1 refused surgery. All 4 operated patients showed multiple lymph node metastases including the subcarinal, hilar and posterior mediastinal nodes.

Two of 4 patients with abnormal carinal aerosol deposition and bronchoscopically widened carinas underwent exploratory thoracotomy, and had advanced metastases. The other 2 patients with bronchial carcinoid survived lobectomy and dissection of the hilar nodes. 4 of 13 patients with no carinal deposition and bronchoscopically normal carinas were operated. 2 underwent left pneumonectomy with minimum mediastinal lymphadenopathy, 1 right lobectomy with dissection of the hilar and mediastinal lymph nodes and 1 left upper lobectomy with minimum mediastinal lymphadenopathy.

To differentiate how carinal aerosol deposition differs in disease entities, the frequency of carinal aerosol deposition was compared as shown in Table 2. Each 
TABLE 2 Carinal aerosol deposition of inhaled aerosol

\begin{tabular}{ccr}
\hline Pulmonary neoplasm & \\
$\% \mathrm{FEV}_{1.0}$ & $\geqq 70$ & $14 / 25=56 \%$ \\
& $<70$ & $24 / 28=86 \%$ \\
Chronic obstructive pulmonary & diseases (COPD) \\
& $<70$ & $3 / 10=30 \%$ \\
Miscellaneous lung diseases & \\
& $\geq 70$ & $8 / 41=20 \%$ \\
& $<70$ & $6 / 19=32 \%$ \\
\hline
\end{tabular}

disease entity was divided into two categories according to the value of the $\% \mathrm{FEV}_{1.0}$. Carinal aerosol deposition was definitely more frequent in patients with pulmonary neoplasm irrespective of the degree of airway obstructive disturbances.

\section{Discussion}

Information regarding the carina is important in determining the therapeutic approach to lung neoplasm. Survival at 5 years following surgery is markedly diminished to a range of 5 to 7 per cent in the presence of mediastinal involvement (Paulson and Urschel 1971). The pathological widening of the carina is only estimated by a direct visualization of the carina by bronchoscopy. Bronchoscopy is easily done nowadays using a flexible fiberoptic bronchoscope by skilled hands (Ikeda 1970), but its performance gives some discomfort to the patient. Aerosol inhalation lung scanning is easy to perform and useful in establishing the aerated space in the lungs, although it has certain limitations (Shibel et al. 1969; Isawa et al. 1970a, 1971b). When combined with perfusion lung scans, it gives a fairly good estimate of regional ventilation (or airway patency) and perfusion relationships (Isawa et al. 1970a, b, 1971a, b, 1972). Although the particle size of the inhaled aerosol is an important problem in determining the site of inhaled aerosol deposition, we estimate it to be less than $3 \mu \mathrm{m}$ in diameter with the equipment used (Isawa et al. 1970a).

Although carinal aerosol deposition is not an exclusively specific finding in patients with pulmonary neoplasm because airway obstructive disturbance also increases the frequency of carinal deposition as shown in Table 2, the scan findings of excessive deposition of inhaled radioaerosol at the carina is helpful in selecting further diagnostic procedures and in planning therapeutic approaches. When abnormal aerosol deposition is found in patients with pulmonary neoplasm, other therapeutic approaches such as the surgical operation may be indicated, because the therapeutic procedure should be conservative in patients whose cancers are not likely to be resectable (Weiss 1974). If no carinal deposition is found, further examinations including mediastinoscopy should be performed to determine whether distant metastases are present or not (Ashbaugh 1970). From the small number of patients operated upon, nothing conclusive could be drawn, but we have limited evidence that actual regional lymphadenopathy is minimum, 
if any, in patient with little or no carinal aerosol deposition.

The airways normally dilate on inspiration and contract on expiration (Dejours 1966). Carinal widening may result from compression and fixation of the carina by lymph node metastases in the mediastinum including the subcarinal nodes (Stradding 1968). Respiratory movement and air flow changes through a narrowed carina are known to cause excessive aerosol deposition resulting from inertial impaction (Isawa et al. 1970a, 1971b). Furthermore impaired mucociliary clearance mechanism due to cancer infiltration at the carina could also be a factor to enhance visualization of carinal radioactivity.

Application of the aerosol inhalation lung scan to pulmonary neoplasm thus provides new diagnostically important information regarding mediastinal lymph nodes metastases in addition to the estimation of regional ventilation and perfusion relationships in the lung parenchyma.

\section{References}

1) Amer. Thorac. Soc. (1962) Definitions and classification of chronic bronchitis, asthma, and pulmonary emphysema. Amer. Rev. resp. Dis., 85, 762-768.

2) Ashbaugh, D.G. (1970) Mediastinoscopy. Arch. Surg., 100, 568-573.

3) Dejours, P. (1966) (translated by Farhi, L.) Chapter 5. Mechanics of ventilation; movements of the bronchi. In: Respirasion, Oxford Univ. Press, New York, pp. 6668.

4) Dore, E.K., Poe, N.D., Ellestad, M.H. \& Taplin, G.V. (1968) Lung perfusion and inhalation scanning in pulmonary emphysema. Amer. J. Roentgenol., 104, 770-776.

5) Ikeda, S. (1970) Flexible bronchofiberscope. Ann. Oto. Rhino. Laryn., 79, 916-923.

6) Isawa, T., Wasserman, K. \& Taplin, G.V. (1970a) Lung scintigraphy and pulmonary function studies in obstructive airway disease. Amer. Rev. resp. Dis., 102, 161-172.

7) Isawa, T., Benfield, J.R., Johnson, D.E. \& Taplin, G.V. (1970b) A comparison of lung scanning and differential bronchospirometry as pulmonary function tests in dogs. $J$. thorac. cardiovasc. Surg., 60, 719-729.

8) Isawa, T., Benfield, J.R., Castagna, J., Johnson, D.E. \& Taplin, G.V. (1971a) Functional assessment of canine lung transplants by radioisotope lung scanning procedures. Amer. Rev. resp. Dis., 103, 76-84.

9) Isawa, T., Hayes, M. \& Taplin, G.V. (1971b) Radioaerosol inhalation lung scanning. Its role in suspected pulmonary embolism. J. nucl. Med., 12, 606-609.

10) Isawa, T., Taplin, G.V., Beazell, J. \& Criley, J.M. (1972) Experimental unilateral pulmonary artery occlusion. Acute and chronic effects on relative inhalation and perfusion. Radiology, 102, 101-109.

11) Paulson, D.L. \& Urschel, H.C., Jr. (1971) Selectivity in the surgical treatment of bronchogenic carcinoma. J. thorac. cardiovasc. Surg., 62, 554-562.

12) Shibel, E.M., Landis, G.A. \& Moser, K.M. (1969) Inhalation lung scanning evaluationradioaerosol versus radioxenon techniques. Dis. Chest, 56, 284-289.

13) Stradding, P. (1968) Chapter 5. In: Diagnostic Bronchoscopy. An Introduction, E. \& S Livingston, Ltd., Edinburgh and London, pp. 72-85.

14) Weiss, W. (1974) Operative mortality and five-year survival rates in men with bronchogenic carcinoma. Chest, 65, 485-487. 